Article

\title{
Extract of Juniperus indica Bertol Synergizes with Cisplatin to Inhibit Oral Cancer Cell Growth via Repression of Cell Cycle Progression and Activation of the Caspase Cascade
}

\author{
Xiao-Fan Huang ${ }^{1,2}$, Kai-Fu Chang ${ }^{1,2}{ }^{\oplus}$, Shan-Chih Lee ${ }^{3,4}{ }^{\text {, Chia-Yu Li }}{ }^{5}$, Hung-Hsiu Liao ${ }^{2}$, \\ Ming-Chang Hsieh ${ }^{2,6, *}$ and Nu-Man Tsai ${ }^{2,6, *}$ \\ 1 Institute of Medicine, Chung Shan Medical University, Taichung 40201, Taiwan; \\ s9870509@gmail.com (X.-F.H.); kfchang1015@gmail.com (K.-F.C.) \\ 2 Department of Medical Laboratory and Biotechnology, Chung Shan Medical University, \\ Taichung 40201, Taiwan; s65874@yahoo.com.tw \\ 3 Department of Medical Imaging and Radiological Sciences, Chung Shan Medical University, \\ Taichung 40201, Taiwan; sclee@csmu.edu.tw \\ 4 Department of Medical Imaging, Chung Shan Medical University Hospital, Taichung 40201, Taiwan \\ 5 Department of Life and Death, Nanhua University, Chiayi 62249, Taiwan; joyce@nhu.edu.tw \\ 6 Clinical Laboratory, Chung Shan Medical University Hospital, Taichung 40201, Taiwan \\ * Correspondence: cshb183@csh.org.tw (M.-C.H.); numan@csmu.edu.tw (N.-M.T.); \\ Tel.: +886-4-2473-0022 (ext. 12411) (N.-M.T.); Fax: +886-4-2324-8171 (N.-M.T.)
}

Academic Editors: Halina Ekiert and Agnieszka Szopa

Received: 21 May 2020; Accepted: 12 June 2020; Published: 13 June 2020

\begin{abstract}
Oral cancer-a type of head and neck cancer-is estimated to be the fifth most common cancer in Taiwan. However, efficacious therapies for oral cancer are still lacking due to drug resistance and recurrence. Consequently, the identification of new anticancer agents for clinical treatment is needed. Juniperus indica Bertol is a plant of the Juniperus genus often used as a treatment in traditional medicine due to its anti-inflammatory, antibacterial and diuretic functions. The biofunctions of Juniperus indica Bertol including its anticancer potential, have not been fully explored. As a result, the aim of this research was to investigate the anticancer activity of Juniperus indica Bertol extract (JIB extract) and determine whether JIB extract has synergistic effects with cisplatin in oral cancer. These results are the first to demonstrate that JIB extract exhibits anticancer capacity and synergizes with cisplatin to treat oral cancer. Our findings indicate that JIB extract has a potential to develop anticancer agent and chemo therapeutic adjuvant for oral cancer.
\end{abstract}

Keywords: oral cancer; cisplatin; synergism; cell apoptosis; Juniperus indica Bertol

\section{Introduction}

Oral cancer is the most common type of head-neck cancer; the Ministry of Health and Welfare has estimated that among cancers, oral cancer had the fifth highest incidence in 2016 in Taiwan. Furthermore, according to the National Cancer Institute, oral cancer accounted for $2.9 \%$ and $1.6 \%$ of the incidence and mortality of all cancers, respectively, in 2017 in the United States. The five-year survival rate of patients with oral cancer decreases significantly with increasing stage, ranging from $77.7 \%$ to $32.8 \%$, and the survival rate drops to $10 \%$ owing to recurrence and metastasis [1-3]. The common therapeutic procedure in oral cancer is first the administration of curable treatments, such as surgery, for early stage oral cancer and palliative treatments, including radiotherapy, chemotherapy, target therapy and combination treatments, for nonsurgical or advanced cases of oral cancer [4].The current treatment 
not clearly improves survival benefits of patients due to the drug resistance, tolerance to chemo-drug toxicity and high recurrent rate. Therefore, development of combination therapy represents a major new trend for oral cancer treatment [5].

Cisplatin is a platinum-based chemotherapeutic drug approved by the FDA for the treatment of advanced ovarian, testicular and bladder cancers in 1978. Several researchers have recently reported that cisplatin is also used in the treatment of various additional cancers, such as cervical cancer, lung cancer, osteosarcoma and neuroblastoma [6]. Although cisplatin displays good therapeutic efficiency in patients, it still causes severe adverse side effects, such as nephrotoxicity, peripheral neuropathy, nausea, vomiting and nephrotoxicity, which is especially lethal due to renal failure [7]. In addition. the recurrence rate of oral cancer within three years is estimated to be approximately $86 \%$. In addition. these tumors are highly metastatic and drug resistant, resulting in noneffective treatment and poor prognosis [1]. Therefore, the need to find an anticancer agent with low toxicity that can ameliorate tumor recurrence is urgent.

The use of conventional medicines combined with complementary and alternative medicines is increasing worldwide $[8,9]$. Furthermore, herbal compounds have shown the potential to synergize with antitumoral drugs to boost therapeutic efficacy and relieve adverse effects [10,11]. Juniperus is a genus of evergreen trees that includes the four species Juniperus viz. Juniperus communis, Juniperus indica Berto., Juniperus recurva and Juniperus squamata. Among these plants, the various biofunctions of Juniperus communis have been fully studied [12-15]. Juniperus indica Bertol also called black Juniper [16] was reported to have antimicrobial activity [17] and cytotoxic activity against brine shrimp eggs [18]. However, the anticancer activity of Juniperus indica Bertol extract (JIB extract) against oral cancer is still not fully understood. Hence, the purpose of the study was to investigate the anticancer potential and synergistic effect of JIB extract in combination with cisplatin to provide alternative treatment for clinicians and patients. We first examined the antiproliferative activity of JIB extract, as it was not yet clear. Our results showed that JIB extract not only inhibited oral cancer cell growth and the induction of apoptosis, but also synergized with cisplatin to downregulate the Akt/mTOR pathway and reduce cell regrowth. Consequently, JIB extract may be utilized as an adjuvant in combination with cisplatin and provide a new therapeutic strategy for oral cancer treatment.

\section{Results}

\subsection{Inhibitory Effect of JIB Extract on Oral Cancer Cell Growth}

To investigate the antiproliferative activity of JIB extract against oral cancer cells, cells were treated with JIB extract for the indicated intervals, and MTT assays were performed. OECM-1 cell viability was reduced by approximately $80 \%$ following treatment with JIB extract at concentrations of $50-200 \mu \mathrm{g} / \mathrm{mL}$. The cell viability of SAS and SCC-25 cells was reduced by approximately $50-60 \%$ following treatment with JIB extract at high concentrations ranging from $50 \mu \mathrm{g} / \mathrm{mL}$ to $200 \mu \mathrm{g} / \mathrm{mL}$ (Figure 1A). Juniperus indica Bertol crude extract inhibited oral cancer cell growth in a dose-dependent manner. $\mathrm{Th}^{\mathrm{IC}} \mathrm{I}_{50}$ of JIB extract in the oral cancer cell lines ranged from $38.12 \pm 0.75 \mu \mathrm{g} / \mathrm{mL}$ to $65.9 \pm 3.93 \mu \mathrm{g} / \mathrm{mL}$ (Table 1). As shown in Figure 1B, cisplatin efficiently inhibited oral cancer cell proliferation in a dose- and time-dependent manner, and its $\mathrm{IC}_{50}$ values ranged from $1.19 \pm 0.01 \mu \mathrm{g} / \mathrm{mL}$ to $25.08 \pm 1.53 \mu \mathrm{g} / \mathrm{mL}$ (Table 1). To test the cytotoxicity of JIB extract on normal cells, MDCK, a kidney epithelial cell line and SVEC cells, an endothelial cell line, were used. The MDCK and SVEC cells were slightly inhibited about $10 \%$ of cell growth by JIB extract at a concentration of $50 \mu \mathrm{g} / \mathrm{mL}$, suggesting that JIB extract is less cytotoxic to normal cells (Figure 1C). As shown in Table 1, the $\mathrm{IC}_{50}$ of JIB extract in the normal cell lines ranged from $73.63 \pm 0.9 \mu \mathrm{g} / \mathrm{mL}$ to $102.59 \pm 14.26 \mu \mathrm{g} / \mathrm{mL}$. Then, cisplatin exerted marked cytotoxic effects against normal cells, and its $\mathrm{IC}_{50}$ values ranged from $1.07 \pm 0.25 \mu \mathrm{g} / \mathrm{mL}$ to $6.08 \pm 0.88 \mu \mathrm{g} / \mathrm{mL}$, indicating the occurrence of previously reported side effects, such as renal toxicity (Figure 1C). Next, to assess the ability of JIB extract to select tumor and normal cells, its selective index (SI) was calculated. The SI of the JIB extract in all cell lines was greater than 1 and ranged from 1.12 to 2.65; however, the SI 
of cisplatin in most cell lines was less than 1 and ranged from 0.18 to 0.96 (Figure 1D). In summary, $\mathrm{JIB}$ extract at a concentration of $50 \mu \mathrm{g} / \mathrm{mL}$ inhibited oral cancer cell growth and showed little cytotoxicity to normal cells. In addition, JIB extract showed greater selective ability than cisplatin.
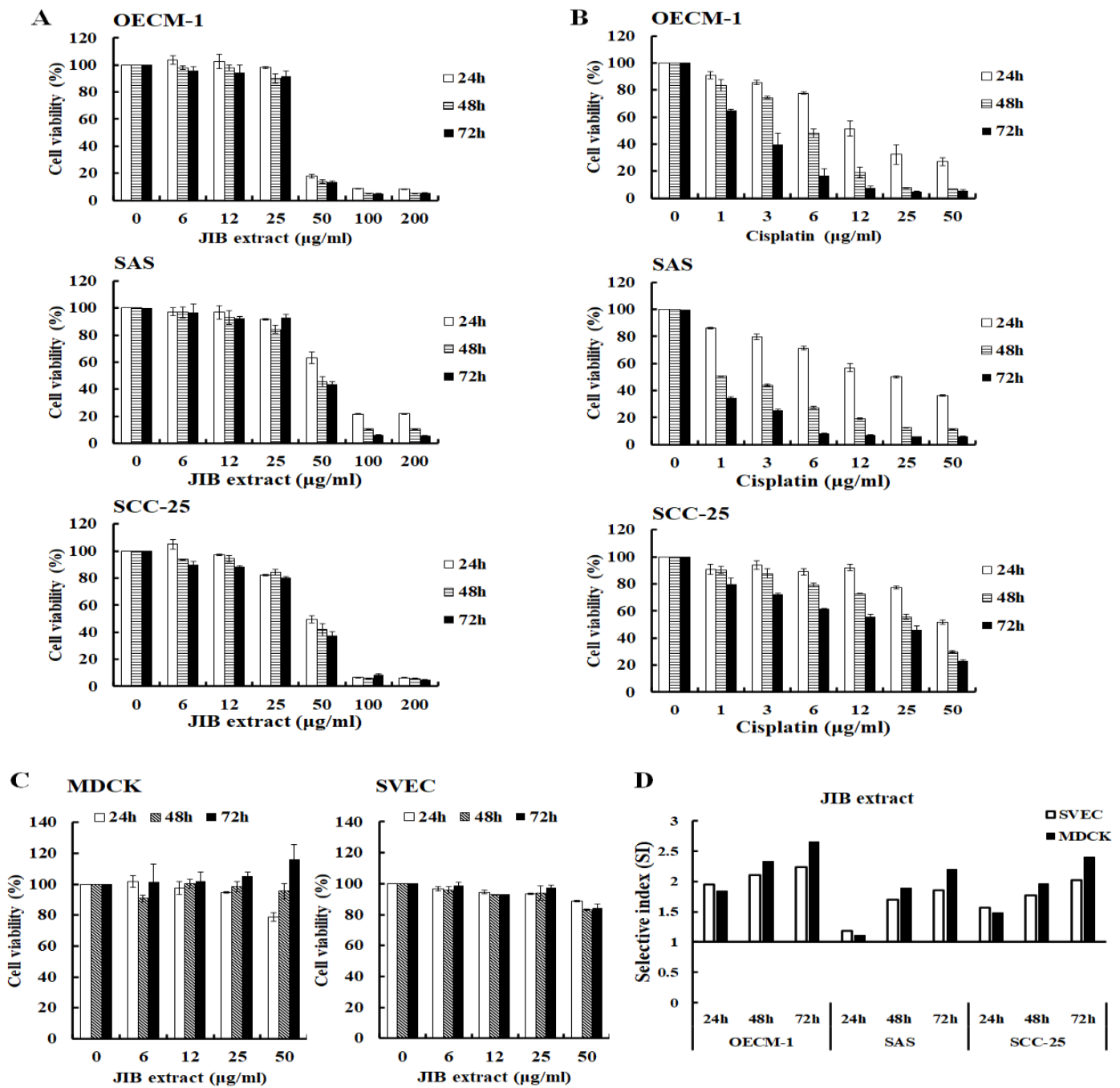

MDCK

$$
\text { SVEC }
$$
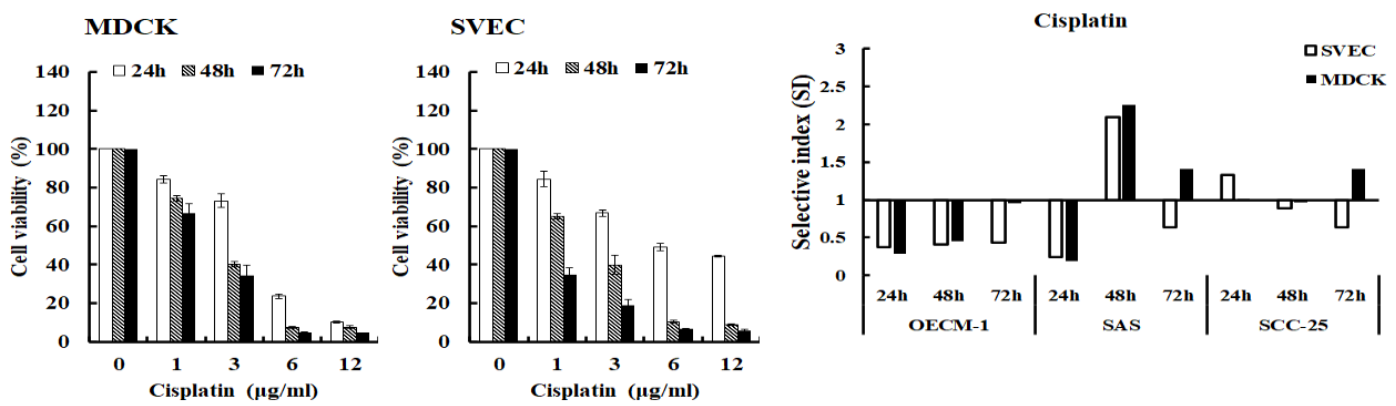

Figure 1. The inhibitory effect of Juniperus indica Bertol crude extract (JIB) on oral cancer cells. Cells were grown in 96well plates and treated with JIB extract or cisplatin at a series of concentrations for 24, 48 and $72 \mathrm{~h}$. The cell viability is presented as the percentage of the mean \pm SD. (A) Growth inhibition curves following treatment with JIB extract. (B) Growth inhibition curves following treatment with cisplatin. (C) Normal cells were treated with JIB extract and cisplatin. (D) Selective index (SI) of JIB extract and cisplatin in oral cancer cell lines. 
Table 1. $\mathrm{IC}_{50}$ values of JIB extract and cisplatin in different oral cancer and normal cell lines.

\begin{tabular}{|c|c|c|c|c|}
\hline Cell Line & Tumor Type & Time (h) & JIB Extract $\mathrm{IC}_{50}$ & Cisplatin $\mathrm{IC}_{50}$ \\
\hline \multicolumn{5}{|c|}{ Oral Cancer Cell Lines } \\
\hline \multirow{3}{*}{ OECM-1 } & \multirow{3}{*}{$\begin{array}{l}\text { Human oral squamous } \\
\text { cancer cell }\end{array}$} & $24 \mathrm{~h}$ & $40 \pm 0$ & $16 \pm 2$ \\
\hline & & $48 \mathrm{~h}$ & $38 \pm 1$ & $6 \pm 1$ \\
\hline & & $72 \mathrm{~h}$ & $39 \pm 1$ & $3 \pm 1$ \\
\hline \multirow{3}{*}{ SAS } & \multirow{3}{*}{$\begin{array}{l}\text { Human oral squamous } \\
\text { cancer cell }\end{array}$} & $24 \mathrm{~h}$ & $66 \pm 4$ & $25 \pm 2$ \\
\hline & & $48 \mathrm{~h}$ & $47 \pm 2$ & $1 \pm 0$ \\
\hline & & $72 \mathrm{~h}$ & $47 \pm 1$ & $2 \pm 0$ \\
\hline \multirow{3}{*}{ SCC-25 } & \multirow{3}{*}{$\begin{array}{c}\text { Human tongue } \\
\text { squamous cancer cell }\end{array}$} & $24 \mathrm{~h}$ & $50 \pm 2$ & $5 \pm 0$ \\
\hline & & $48 \mathrm{~h}$ & $45 \pm 2$ & $3 \pm 0$ \\
\hline & & $72 \mathrm{~h}$ & $43 \pm 1$ & $2 \pm 0$ \\
\hline \multicolumn{5}{|c|}{ Normal Cell Lines } \\
\hline \multirow{3}{*}{ SVEC } & \multirow{3}{*}{ Mouse endothelial cell } & $24 \mathrm{~h}$ & $78 \pm 1$ & $6 \pm 1$ \\
\hline & & $48 \mathrm{~h}$ & $80 \pm 2$ & $3 \pm 0$ \\
\hline & & $72 \mathrm{~h}$ & $86 \pm 4$ & $1 \pm 0$ \\
\hline \multirow{3}{*}{ MDCK } & \multirow{3}{*}{$\begin{array}{l}\text { Canine normal } \\
\text { epithelial cell }\end{array}$} & $24 \mathrm{~h}$ & $74 \pm 1$ & $5 \pm 1$ \\
\hline & & $48 \mathrm{~h}$ & $89 \pm 1$ & $3 \pm 0$ \\
\hline & & $72 \mathrm{~h}$ & $103 \pm 14$ & $2 \pm 0$ \\
\hline
\end{tabular}

Note: values presented as mean $\pm \mathrm{SD}$ at different time points $(\mu \mathrm{g} / \mathrm{mL})$. $\mathrm{IC}_{50}: 50 \%$ inhibitory concentration.

\subsection{Synergistic Effect of JIB Extract Plus Cisplatin on OECM-1 Cells}

The former results indicated that OECM-1 cells were the most sensitive to JIB extract treatment; hence, OECM-1 cells were used in the follow-up experiments. To determine whether JIB extract plus cisplatin would exert a synergistic effect on OECM-1 cells, an MTT assay was performed to determine the inhibitory effect of the treatments. OECM-1 cells were treated with JIB extract and cisplatin for the indicated time intervals. Cells were treated with cisplatin $(3 \mu \mathrm{g} / \mathrm{mL})$ combined with JIB extract $(0-80 \mu \mathrm{g} / \mathrm{mL})$; the cell viability was reduced by approximately $20-30 \%$ when cells were treated with JIB extract at a concentration of 10 or $20 \mu \mathrm{g} / \mathrm{mL}$ compared with treatment with JIB extract only (Figure 2). Conversely, in OECM-1 cells treated with JIB extract $(30 \mu \mathrm{g} / \mathrm{mL})$ in combination with cisplatin $(0-4 \mu \mathrm{g} / \mathrm{mL})$, the cell viability was diminished by approximately $20-60 \%$ when the concentration of cisplatin ranged from 0.25 to $2 \mu \mathrm{g} / \mathrm{mL}$ in comparison with treatment with cisplatin only (Figure 2). Then, the combination index (CI) was evaluated, and a CI value less than 1 indicated synergy. JIB extract plus cisplatin had a synergistic effect, and the CI values were $0.75,0.60$ and 0.42 at 24,48 and $72 \mathrm{~h}$, respectively. 


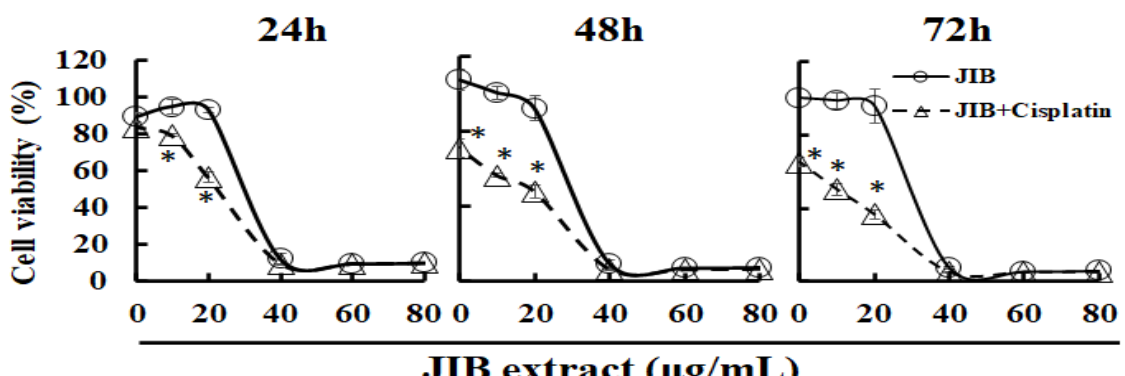

JIB extract $(\mu \mathrm{g} / \mathrm{mL})$

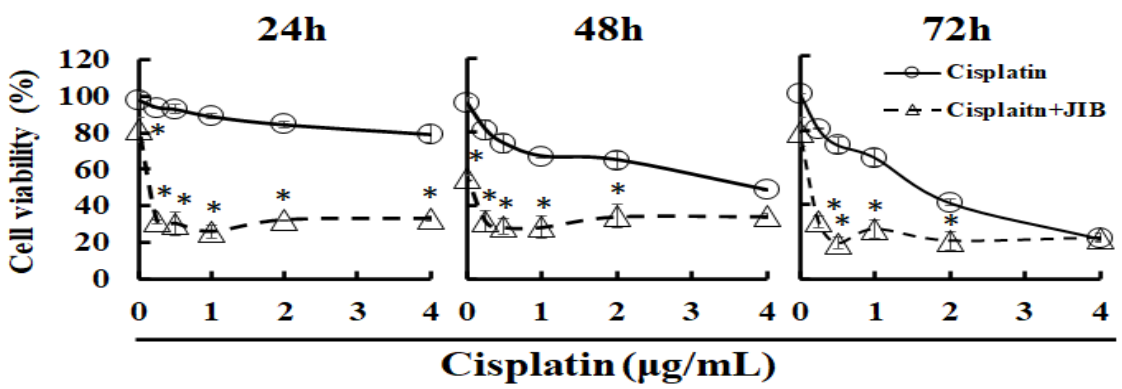

\begin{tabular}{cc}
\hline JIB extract plus Cisplatin & Combination index (CI) \\
\hline $24 \mathrm{~h}$ & 0.75 \\
\hline $48 \mathrm{~h}$ & 0.60 \\
\hline $72 \mathrm{~h}$ & 0.42
\end{tabular}

Figure 2. Effect of the combination of JIB extract and cisplatin on OECM-1 cells. OECM- 1 cells $\left(5 \times 10^{3}\right)$ were seeded in 96 well plates and simultaneously treated with JIB extract and cisplatin for 24, 48 and $72 \mathrm{~h}$. Cell viability is shown as the mean $\pm \mathrm{SD}$, and the experiment was performed in triplicate. $(p<0.05)$.

\subsection{Obstruction Cell Cycle Progression of JIB Extract and Combinational Treatment}

According to the above data, we chose an appropriate concentration of JIB extract $(30 \mu \mathrm{g} / \mathrm{mL})$ that had a synergistic effect with cisplatin $(3 \mu \mathrm{g} / \mathrm{mL})$. To fully explore the anticancer mechanisms of JIB extract plus cisplatin, we first wondered whether this combination would affect the cell cycle progression of OECM-1 cells treated for different intervals. After treatment, the cell cycle distribution was analyzed, the results of which are shown in Figure 3A,B. JIB extract induced significant cell cycle arrest at $G_{0} / G_{1}$ phase, with the proportion of cells at this stage ranging from $55.22 \pm 0.46 \%$ to $74.38 \pm 0.47 \%$, and reduced the proportion of cells at the $S$ and $\mathrm{G}_{2} / \mathrm{M}$ phases. Cisplatin initially blocked cell cycle progression at $G_{0} / G_{1}$ phase and decreased the proportion of cells at $G_{2} / M$ phase, which ranged from $27.76 \pm 0.23 \%$ to $44.81 \pm 0.59 \%$ following treatment with cisplatin for 6 to $48 \mathrm{~h}$. Following combination treatment, the proportion of cells arrested at $S$ phase ranged from $17.02 \pm 0.31 \%$ to $22.99 \pm 1.60 \%$ with $0-12 \mathrm{~h}$ of treatment, after which the proportion of the cell population at G2/M phase increased, ranging from $27.76 \pm 0.23 \%$ to $40.75 \pm 0.29 \%$ for $0-48 \mathrm{~h}$ of treatment, in contrast to the reduction in the proportion of cells at $\mathrm{G}_{0} / \mathrm{G}_{1}$ phase (Figure $3 \mathrm{~B}$ ). These results indicated that JIB extract or cisplatin only induced cell cycle arrest at $G_{0} / G_{1}$ phase or $G_{2} / M$ phase, respectively, while JIB extract plus cisplatin strongly induced cell cycle arrest at $\mathrm{G}_{2} / \mathrm{M}$ phase. As a result, we explored regulators of the cell cycle that may be affected by JIB extract and cisplatin. As shown in Figure 4A, the Western blot results showed that treatment with JIB extract or cisplatin alone reduced the protein expression of $R b$, $p-R b, c d k 2$, cdk4, cyclin D and cyclin B, resulting in cell cycle arrest at $G_{0} / G_{1}$ phase or $G_{2} / M$ phase, respectively. Moreover, JIB extract in combination with cisplatin diminished expression of these cell cycle-related proteins, especially $\mathrm{Rb}, \mathrm{p}-\mathrm{Rb}, \mathrm{cdk} 2$ and cyclin $\mathrm{D}$, to a greater extent than treatment with a 
single drug. Consequently, JIB extract plus cisplatin had a synergistic effect and mediated cell cycle progression at $\mathrm{G}_{2} / \mathrm{M}$ phase in OECM-1 cells.
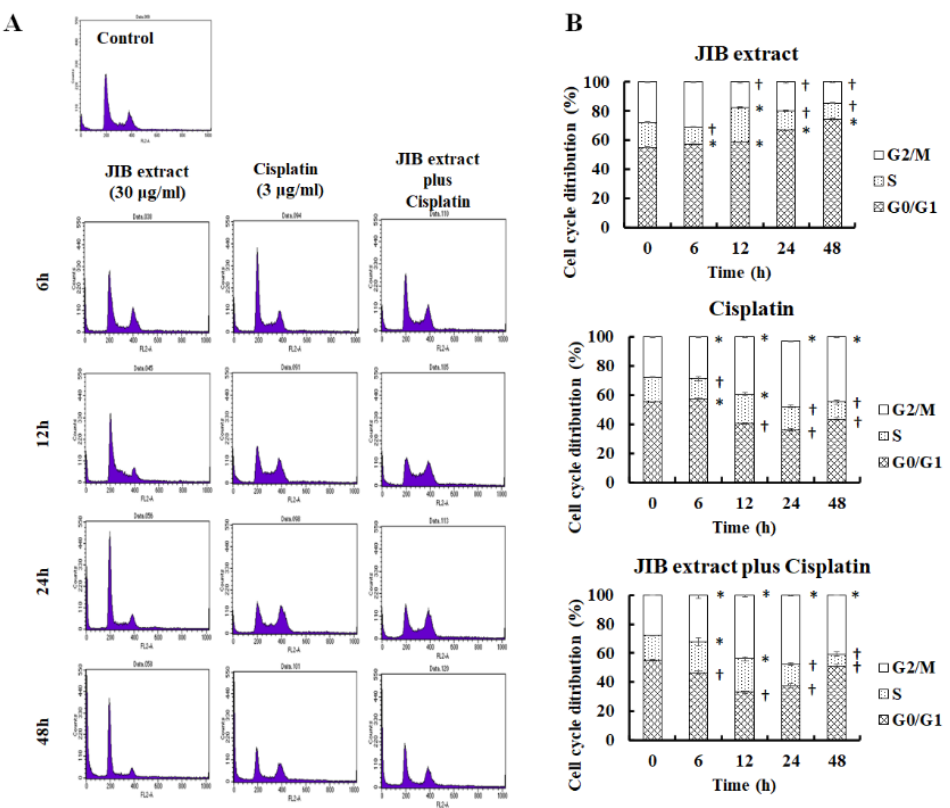

Figure 3. Cell cycle distribution of OECM-1 cells after treatment with JIB extract plus cisplatin. A total of $2 \times 10^{6}$ OECM- 1 were seeded in $10 \mathrm{~cm}$ dishes and treated with JIB extract $(30 \mu \mathrm{g} / \mathrm{mL})$ and cisplatin $(3 \mu \mathrm{g} / \mathrm{mL})$ for $6,12,24$ and $48 \mathrm{~h}$. After the cells were collected, the cell cycle was analyzed by flow cytometry, and cell cycle progression was observed. (A) Image showing the cell cycle distribution; (B) quantitative cell cycle data. ${ }^{*}$ - significantly increased compared with the control; ${ }^{\dagger}$ - significantly decreased compared with the control. $(p<0.05)$.
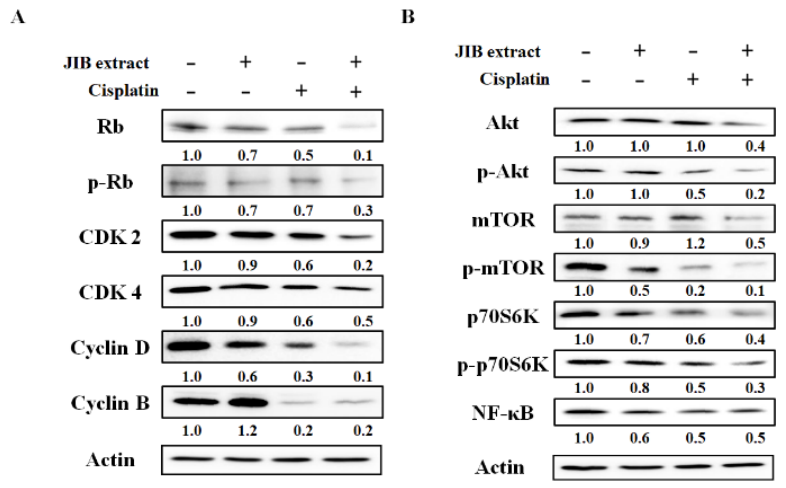

Figure 4. Cell proliferation-related protein expression after treatment with JIB extract plus cisplatin. After treatment, OECM-1 cells were harvested, and total protein was extracted by lysis buffer. Total proteins were quantified by BCA assay, and western blotting was performed to detect changes in protein expression due to combination treatment. (A) Cell cycle-related protein expression. (B) Akt/mTOR signaling protein expression.

\subsection{Inhibitory Effect of JIB Extract Plus Cisplatin on Akt/mTOR Pathway}

The former results indicated that JIB extract or combination treatment exerts antiproliferative effects, and Akt/mTOR signaling is a general pathway in tumorigenesis that plays a vital role in the regulation of cell proliferation and survival. Therefore, we aimed to elucidate whether JIB extract synergized with cisplatin to repress Akt/mTOR signaling in OECM-1 cells. JIB extract plus cisplatin enhanced the reduction in the levels of Akt, mTOR and P70S6K and their phosphorylated protein forms by approximately 2 -fold (Figure $4 \mathrm{~B}$ ). In addition, NF- $\mathrm{kB}$ protein expression was detected, and 
combination treatment reduced NF- $\kappa$ B protein levels, while JIB extract or cisplatin alone had no marked effect on NF- $\kappa B$ protein levels (Figure 4B). These results revealed that JIB extract synergizes with cisplatin to inhibit cell proliferation by obstructing Akt/mTOR signaling.

\subsection{Induction of Apoptosis in JIB Extract and Combinational Treatment}

To further clarify the induction of cell death by JIB extract or combination treatment, a TUNEL assay was performed. JIB extract induced cell death by triggering OECM-1 cell apoptosis, similar to previously reported cisplatin-mediated induction of cell apoptosis. Additionally, JIB extract in combination with cisplatin induced OECM-1 cell death by activating apoptosis and DNA fragments, anoikis and apoptotic body formation were observed (Figure 5A). Next, general caspase activity after treatment was detected. Treatment with either JIB extract or cisplatin only increased general caspase activity at all time points. Combination treatment with JIB extract and cisplatin increased the caspase activity to the greatest extent compared with treatment with each drug alone (Figure 5B). These results demonstrated that JIB extract not only induced cell apoptosis, but also synergized with cisplatin to increase caspase activation.

A

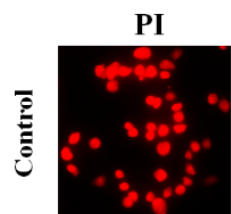

TUNEL

B
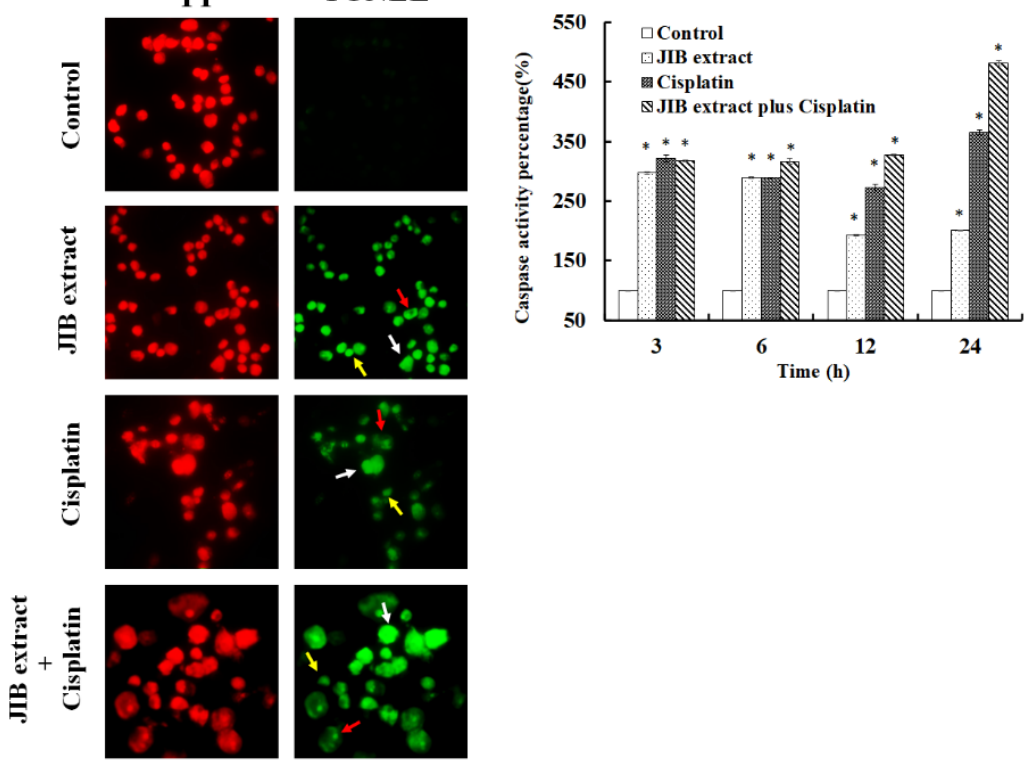

Figure 5. Induction of the caspase cascade after treatment with JIB extract plus cisplatin. OECM-1 cells were treated with JIB extract, cisplatin or a combination of JIB extract and cisplatin for $48 \mathrm{~h}$. Then, the cells were collected, and TUNEL staining was carried out according to the manufacturer's instructions. Red: PI; green: TUNEL-positive; white arrow: DNA fragments; red arrow: anoikis; yellow arrow: apoptotic bodies. (A) TUNEL staining of OECM-1 cells after drug treatment. (B) The caspase activity of OECM-1 cells treated after drug treatment for 3, 6, 12 and $24 \mathrm{~h}$. * - significant difference between the control group and treatment groups. $(p<0.05)$.

\subsection{Reduction of OECM-1 Cell Regrowth in JIB Extract Plus Cisplatin}

During the therapeutic period for oral cancer patients, the recurrence rate is an important factor that affects prognosis. As a result, we wondered whether treatment with JIB extract in combination with cisplatin would reduce cell regrowth or prolong the inhibition of cell regrowth in vitro. JIB extract at a concentration of $30 \mu \mathrm{g} / \mathrm{mL}$ had a slight inhibitory effect on cell growth in OECM-1 cells grown continuously for 16 days. At the beginning of the treatment period, cisplatin had a strong inhibitory effect on OECM-1 cell growth, with an absorbance of 0.2 measured in the cell growth assay; however, after 9 and 16 days of treatment, OECM-1 cells had regrown, and an absorbance of 0.4 was recorded. When OECM-1 cells were treated with JIB extract in combination with cisplatin, combination treatment 
continuously inhibited cell growth, and the absorbance of cells under combination treatment was maintained below 0.2 (Figure 6). As a result, JIB extract synergized with cisplatin to mitigate the regrowth of OECM-1 cells, revealing that it may decrease recurrence after surgery or therapeutic procedures.
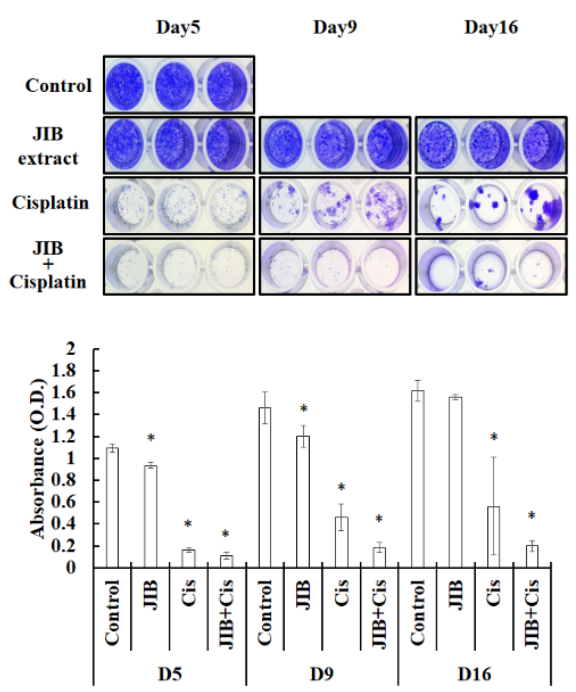

Figure 6. JIB extract plus cisplatin inhibited regrowth. Cells were treated with JIB extract, cisplatin or a combination of JIB extract and cisplatin for 5, 9 and 16 days, and fresh drugs were added every three days. After treatment, cells were stained with $0.1 \%$ crystal violet and photographed. The crystals were dissolved in 10\% acetic acid, and the O.D. (Optical density) at $590 \mathrm{~nm}$ was measured. * - significant difference between the control and drug treatment groups. $(p<0.05)$.

\section{Discussion}

With the increasing incidence of cancer, several anticancer agents are under discovery and chemically modified to improve the therapeutic treatment efficacy. Although many chemotherapeutic drugs are continuously discovered, avoiding adverse effects from chemotherapeutic drugs during treatments is difficult [19]. For instance, cisplatin has been reported to have unpredictive nephrotoxicity and immunosuppressive effects during therapy. Nonetheless, cisplatin is the first-line chemo-drug for advanced non-small cell lung cancer cells and patients with locally advanced head and neck cancers, including oral cancer, oropharyngeal cancer, hypopharyngeal cancer and laryngeal cancer [20]. Moreover, during treatment, drug resistance may develop, necessitating higher doses to achieve former antitumor effects; however, higher doses may exaggerate severe side effects [21]. Accordingly, combination treatment with various drugs with distinct mechanisms is a therapeutic strategy that may potentiate the therapeutic efficacy of each drug [22-25]. In view of these problems, combined treatment with other anticancer agents is an effective strategy to overcome those limitations for clinical application.

As a result, herein, we utilized plant extract to achieve the goal of inhibiting tumor growth and reducing cytotoxicity to alleviate possible side effects. Various natural plant extract has been studied and have developed as anticancer agents in current standard treatment, such as vincristine and paclitaxel. Juniperus indica Bertol has been used in daily for prevention of disease and literature search revealed few studies on Juniperus indica Bertol In this study, we first found that JIB extract demonstrated anticancer activity against oral cancer cells. In addition, our results indicated that JIB extract has a better selectivity index than cisplatin. These results revealed that the application of JIB extract for clinical treatment may decrease the risk of side effects in patients. The anticancer activity of JIB extract was first found to inhibit oral cancer cell growth by blocking cell cycle progression, repressing Akt/mTOR signaling and triggering cell apoptosis. Hence, JIB extract has the potential to be used as an adjuvant in combination with chemo-drugs and to promote treatment effects. Therefore, we have provided experimental evidence that the combination of JIB extract and cisplatin may enhance 
therapeutic potential in oral cancer treatment. In addition, JIB extract and cisplatin are regulated through inhibition of the cell cycle process, which is mediated by Rb, cdks and cyclins. Our results revealed the novel and synergistic functions of JIB extract and cisplatin, resulting in cell cycle arrest at $\mathrm{G}_{2} / \mathrm{M}$ phase and further reducing cell cycle-related protein expression. The findings in the study indicate that JIB extract in combination with cisplatin enhanced the inhibition of Akt/mTOR signaling to rescue cell proliferation. Additionally, the combination of JIB extract and cisplatin was more effective in killing oral cancer cells than either single treatment. The combination of JIB extract with cisplatin prevented and prolonged cell growth in vitro, suggesting that combination treatment may reduce the risk of recurrence or drug-resistant cell growth. Taken together, our results verified that JIB extract may be a safe agent to reduce the risk of side effects, making it an attractive candidate for future clinical assessment with cisplatin.

\section{Materials and Methods}

\subsection{Cell Culture and Reagents}

The immortalized OECM-1 human gingival squamous cancer cell line was developed by C.Y. Yang and Dr. C.L. Meng [26], and SAS human tongue squamous cancer cells were provided by Dr. Cheng-Chia Yu from Chung Shan Medical University (Taichung, Taiwan). SCC-25 human tongue squamous cancer cells, SVEC mouse vascular endothelial cells and MDCK canine kidney epithelial cells were obtained from American Type Culture Collection (Manassas, VA, USA) or the Bioresource Collection and Research Center (Hsinchu, Taiwan). OECM-1, SEVC and MDCK cells were cultured in DMEM with $10 \%$ FBS, $1 \%$ sodium pyruvate, $1 \%$ HEPES and $1 \%$ penicillin/streptomycin. SAS and SSC-25 cells were cultured in DMEM/F12 medium containing 10\% FBS, $1 \%$ sodium pyruvate, $1 \%$ HEPES, $1 \%$ penicillin/streptomycin and $0.1 \%$ hydrocortisone. All the cell culture reagents were purchased from Gibco (Grand Island, NY, USA). The cells were cultured in $5 \% \mathrm{CO}_{2}$ incubators at $37^{\circ} \mathrm{C}$ and passaged with $0.05 \%$ trypsin-EDTA for follow-up treatment.

\subsection{Juniperus Indica Bertol Crude Extract (JIB extract) Preparation}

Crude extract from Juniperus indica Bertol was obtained from PHOENIX (Red Bank, NJ, USA) and extracted by steam distillation. The crude extract of the liquid oil was collected and maintained in a brown glass bottle away from light at $4{ }^{\circ} \mathrm{C}$. For experimental application, JIB extract was initially dissolved in DMSO and applied at $\mu \mathrm{g} / \mathrm{mL}$ concentrations.

\subsection{MTT Proliferation Assay}

Cell proliferation was determined by MTT colorimetric assay. Briefly, OECM-1, SAS and SSC-25 $\left(5 \times 10^{3}\right.$ cells/100 $\mu \mathrm{L} /$ well $)$ or MDCK and SVEC $\left(1 \times 10^{4} / 100 \mu \mathrm{L} /\right.$ well $)$ cells were seeded in 96 well plates and treated with JIB extract $(0-200 \mu \mathrm{L} / \mathrm{mL})$ or cisplatin $(0-50 \mu \mathrm{L} / \mathrm{mL})$ for 24,48 and $72 \mathrm{~h}$ as experimental groups, and cells were left untreated as a control group. Following incubation, the cells were incubated with MTT solution $(500 \mu \mathrm{L} / \mathrm{mL})$ for $8 \mathrm{~h}$. After discarding the MTT solution, the formazan crystals were dissolved with dimethyl sulfoxide, and the absorbance at $550 \mathrm{~nm}$ was detected with a SpectraMax M5 microplate reader (Molecular Devices, San Jose, CA, USA). Cell viability was expressed as the percentage of treated cells over control cells. The percentage of DMSO in the wells was less than $0.2 \%$. All the experiments were independently performed triplicated. The selective index (SI) was defined as the ratio of the $\mathrm{IC}_{50}$ in normal cells to the $\mathrm{IC}_{50}$ in tumor cells. An SI greater than 1 indicated greater selectivity for tumor cells, and an SI less than 1 indicated worse selectivity for tumor cells.

\subsection{Synergistic Evaluation}

Cells $\left(5 \times 10^{3}\right.$ cells $/ 100 \mu \mathrm{L} /$ well $)$ were seeded in 96 well plates for follow-up treatment as follows: synergistic treatment I: (1) JIB extract $(0,10,20,40,60$ and $80 \mu \mathrm{L} / \mathrm{mL})$ and $3 \mu \mathrm{L} / \mathrm{mL}$ cisplatin or (2) JIB extract $(0,10,20,40,60$ and $80 \mu \mathrm{L} / \mathrm{mL})$, synergistic treatment II: (1) cisplatin $(0,0.25,0.5,1$, 
2 and $4 \mu \mathrm{L} / \mathrm{mL}$ ) and $30 \mu \mathrm{L} / \mathrm{mL}$ JIB extract or (2) cisplatin $(0,0.25,0.5,1,2$ and $4 \mu \mathrm{L} / \mathrm{mL})$. All drug treatment groups were incubated with the drugs for 24,48 and $72 \mathrm{~h}$. Then, the procedure described for the MTT proliferation assay was carried out. The experiments were independently performed triplicated. Drug combinations were evaluated by the combination index $(\mathrm{CI})$, which was calculated as the following equation: $\mathrm{CI}=\mathrm{IC}_{50}$ of synergistic treatment $\mathrm{I} / \mathrm{IC} \mathrm{C}_{50}$ of JIB extract $+\mathrm{IC}_{50}$ of synergistic treatment $\mathrm{II} / \mathrm{I} \mathrm{C}_{50}$ of cisplatin. $\mathrm{CI}$ values significantly less than 1.0 indicated synergy.

\subsection{Cell Cycle Analysis}

Cells were cultured in $10 \mathrm{~cm}$ dishes at a density of $2 \times 10^{6}$ overnight and treated with the indicated drugs for $0,6,12,24$ and $48 \mathrm{~h}$ as follows: JIB extract only: $30 \mu \mathrm{L} / \mathrm{mL}$ JIB extract, cisplatin only: $3 \mu \mathrm{L} / \mathrm{mL}$ cisplatin, and synergistic treatment: $30 \mu \mathrm{L} / \mathrm{mL} \mathrm{JIB} \mathrm{extract} \mathrm{and} 3 \mu \mathrm{L} / \mathrm{mL}$ cisplatin. PI dye was utilized to analyze the DNA content during the cell cycle. After the cells were harvested, they were incubated with PI $(40 \mu \mathrm{L} / \mathrm{mL})$ and RNase $(100 \mu \mathrm{L} / \mathrm{mL})$ at $4{ }^{\circ} \mathrm{C}$ overnight. The cell cycle distribution was analyzed with a FACSCalibur (BD, Franklin Lakes, NJ, USA), and data were analyzed by CellQuest software (version 1.2, BD, Franklin Lakes, NJ, USA). All the experiments were independently carried out triplicated.

\subsection{Western Blot Analysis}

Cells were grown in $10 \mathrm{~cm}$ dishes overnight and administered the following treatments for $48 \mathrm{~h}$ : JIB extract $(30 \mu \mathrm{L} / \mathrm{mL})$, cisplatin $(3 \mu \mathrm{L} / \mathrm{mL})$ and cisplatin plus JIB extract. Proteins were harvested and quantified by BCA assay (Thermo Fisher Scientific, Waltham, MA USA). After that, total proteins were resolved by $8-12 \%$ SDS-PAGE and transferred to PVDF membranes by electroblotting. The PVDF membranes were then blocked with skim milk and incubated with primary antibodies overnight at $4{ }^{\circ} \mathrm{C}$. After washing, appropriate secondary antibodies were added for reaction, and horseradish peroxidase was then added for incubation at room temperature for $2 \mathrm{~h}$. To visualize the protein bands, T-Pro LumiFast Plus chemiluminescence detection reagent (T-Pro Biotechnology, New Taipei County, Taiwan) was utilized with exposure to chemiluminescence light. Bands were quantified using ImageJ software (NIH, Bethesda, MD, USA). All the antibodies were purchased from Santa Cruz Biotechnology (Dallas, TX, USA). These experiments were independently achieved duplicated.

\subsection{General Caspase Activity Assay}

Caspase activity was determined using a Cell Meter Fluorometric caspase activity assay kit (AAT Bioquest, Sunnyvale, CA, USA). After cells were harvested by $0.05 \%$ trypsin, they were incubated with $500 \mu \mathrm{L}$ of caspase activity solution for $4 \mathrm{~h}$. Then, the cells were centrifuged, the supernatant was discarded, and $500 \mu \mathrm{L}$ of assay buffer was added for flow cytometry. The data were analyzed by CellQuest (Becton Dickinson, Franklin Lakes, NJ, USA). The experiments were independently accomplished triplicated.

\subsection{TUNEL Assay}

An in situ cell death detection kit (Roche, Basel, Switzerland) was used following the manufacturer's instructions. In brief, the cells were incubated in $10 \%$ neutral buffer formalin for $10 \mathrm{~min}$ and then fixed with methanol in $3 \% \mathrm{H}_{2} \mathrm{O}_{2}$ for $10 \mathrm{~min}$ on culture slides. After exposure to $0.1 \%$ Triton X-100 for $2 \mathrm{~min}, 50 \mu \mathrm{L}$ of TUNEL reaction solution was added and incubated for $2 \mathrm{~h}$ at $37^{\circ} \mathrm{C}$. Nuclear staining was performed using PI as a counterstain. Photographs were taken at $400 \times$ magnification and analyzed by Adobe Photoshop CS3 Extended version10.0 (Adobe, San Jose, CA, USA). The experiments were independently performed triplicated. 


\subsection{In vitro Resistance Assay}

Cells were grown in 96 well plates at a density of 800 cells/100 $\mu \mathrm{L}$ and treated with JIB extract only $(15 \mu \mathrm{g} / \mathrm{mL})$, cisplatin only $(0.75 \mu \mathrm{g} / \mathrm{mL})$ or a combination of JIB extract and cisplatin for 5, 9 and 16 days. The drugs were administered every 3 days to ensure drug activity. After treatment, cells were fixed with $10 \%$ methanol for $10 \mathrm{~min}$ and stained with $0.1 \%$ crystal violet for $10 \mathrm{~min}$. Finally, the cells were washed with PBS buffer, the colored crystals were dissolved with $10 \%$ acetic acid, and the absorbance at $590 \mathrm{~nm}$ was measured. The experiments were independently performed triplicated. Photographs were analyzed by Adobe Photoshop CS3 Extended version10.0 (Adobe, San Jose, CA, USA).

\subsection{Statistical Analysis}

Data are expressed as the mean \pm standard deviation (SD). Statistical significance differences were determined by Student's two-tailed $t$-test. A $p$ value $<0.05$ indicates statistical significance.

Author Contributions: Conceptualization, N.-M.T. and M.-C.H.; methodology, X.-F.H., K.-F.C. and H.-H.L.; software, X.-F.H., K.-F.C. and H.-H.L.; validation, X.-F.H., K.-F.C. and H.-H.L.; formal analysis, X.-F.H. and H.-H.L.; investigation, X.-F.H. and H.-H.L.; resources, C.-Y.L., S.-C.L. and M.-C.H.; data curation, N.-M.T. and H.-H.L.; writing - original draft preparation, X.-F.H., K.-F.C. and N.-M.T.; writing - review and editing, X.-F.H., K.-F.C., S.-C.L. and N.-M.T.; visualization, N.-M.T. and M.-C.H.; supervision, N.-M.T.; project administration, N.-M.T.; funding acquisition, N.-M.T. and M.-C.H. All authors have read and agreed to the published version of the manuscript.

Funding: This research grant CSH-2015-A-015, CSH-2014-C-031 and CSH-2015-C-016 was funded by Chung Shan Medical University Hospital, Taiwan.

Acknowledgments: We grateful to Instrument Center of Chung Shan Medical University, which is supported by the National Science Council, the Ministry of Education, and Chung Shan Medical University for facilities, such as ZEISS Axio Imager A2 microscopy throughout the experimental work.

Conflicts of Interest: There are no conflicts of interest.

\section{References}

1. Da Silva, S.D.; Hier, M.; Mlynarek, A.; Kowalski, L.P.; Alaoui-Jamali, M.A. Recurrent oral cancer: Current and emerging therapeutic approaches. Front. Pharmacol. 2012, 3, 149. [CrossRef] [PubMed]

2. Larizadeh, M.H.; Shabani, M. Survival Following Non Surgical Treatments for Oral Cancer: A Single Institutional Result. Asian Pac. J. Cancer Prev. 2012, 13, 4133-4136. [CrossRef] [PubMed]

3. Warnakulasuriya, S. Global epidemiology of oral and oropharyngeal cancer. Oral Oncol. 2009, 45, 309-316. [CrossRef] [PubMed]

4. Lee, J.C.; Chung, L.C.; Chen, Y.J.; Feng, T.H.; Juang, H.H. N-myc downstream-regulated gene 1 downregulates cell proliferation, invasiveness, and tumorigenesis in human oral squamous cell carcinoma. Cancer Lett. 2014, 355, 242-252. [CrossRef] [PubMed]

5. Lo, W.-L.; Kao, S.-Y.; Chi, L.-Y.; Wong, Y.-K.; Chang, R.C.-S. Outcomes of oral squamous cell carcinoma in Taiwan after surgical therapy: Factors affecting survival. J. Oral Maxillofac. Surg. 2003, 61, 751-758. [CrossRef]

6. Florea, A.M.; Busselberg, D. Cisplatin as an anti-tumor drug: Cellular mechanisms of activity, drug resistance and induced side effects. Cancers 2011, 3, 1351-1371. [CrossRef]

7. Siddik, Z.H. Cisplatin: Mode of cytotoxic action and molecular basis of resistance. Oncogene 2003, 22, 7265-7279. [CrossRef]

8. Palmioli, A.; Ciaramelli, C.; Tisi, R.; Spinelli, M.; De Sanctis, G.; Sacco, E.; Airoldi, C. Natural Compounds in Cancer Prevention: Effects of Coffee Extracts and Their Main Polyphenolic Component, 5-O-Caffeoylquinic Acid, on Oncogenic Ras Proteins. Chem. Asian J. 2017, 12, 2457-2466. [CrossRef]

9. Lin, W.F.; Zhong, M.F.; Zhou, Q.H.; Zhang, Y.R.; Wang, H.; Zhao, Z.H.; Cheng, B.B.; Ling, C.Q. Efficacy of complementary and integrative medicine on health-related quality of life in cancer patients: A systematic review and meta-analysis. Cancer Manag. Res. 2019, 11, 6663-6680. [CrossRef] 
10. Lin, S.R.; Chang, C.H.; Hsu, C.F.; Tsai, M.J.; Cheng, H.; Leong, M.K.; Sung, P.J.; Chen, J.C.; Weng, C.F. Natural compounds as potential adjuvants to cancer therapy: Preclinical evidence. Br. J. Pharmacol. 2019, 177, 1409-1423. [CrossRef]

11. Pezzani, R.; Salehi, B.; Vitalini, S.; Iriti, M.; Zuniga, F.A.; Sharifi-Rad, J.; Martorell, M.; Martins, N. Synergistic Effects of Plant Derivatives and Conventional Chemotherapeutic Agents: An Update on the Cancer Perspective. Medicina 2019, 55, 110. [CrossRef] [PubMed]

12. Janku, I.; Hava, M.; Motl, O. [Diuretic substance from juniper (Juniperus communis L.)]. Experientia 1957, 13, 255-256. [CrossRef] [PubMed]

13. Lantto, T.A.; Laakso, I.; Dorman, H.J.; Mauriala, T.; Hiltunen, R.; Koks, S.; Raasmaja, A. Cellular Stress and p53-Associated Apoptosis by Juniperus communis L. Berry Extract Treatment in the Human SH-SY5Y Neuroblastoma Cells. Int. J. Mol. Sci. 2016, 17, 1113. [CrossRef] [PubMed]

14. Al-Attar, A.M.; Alrobai, A.A.; Almalki, D.A. Protective effect of olive and juniper leaves extracts on nephrotoxicity induced by thioacetamide in male mice. Saudi J. Biol. Sci. 2017, 24, 15-22. [CrossRef]

15. Singh, H.; Prakash, A.; Kalia, A.N.; Majeed, A.B. Synergistic hepatoprotective potential of ethanolic extract of Solanum xanthocarpum and Juniperus communis against paracetamol and azithromycin induced liver injury in rats. J. Tradit. Complement Med. 2016, 6, 370-376. [CrossRef]

16. Adams, R.P.; Chaudhary, R.P. Leaf Essential Oil of Juniperus indica Bertol. from Nepal. J. Essent. Oil Res. 1996, 8, 677-680. [CrossRef]

17. Lohani, H.; Haider, S.Z.; Chauhan, N.; Sharma, M. Essential oil composition of leaves and berries of Juniperus communis and Juniperus indica from Uttarakhand Himalaya. J. Med. Arom. Plants Sci. 2010, 32, $199-201$.

18. Mahajan, B.; Shrestha, T.; Gyawali, R. Antibacterial and cytotoxic activity of JUNIPERUS Indica Bertol from Nepalese Himalaya. Int. J. Pharm. Sci. Res. 2012, 3, 1104-1107.

19. Shanmugam, M.K.; Lee, J.H.; Chai, E.Z.; Kanchi, M.M.; Kar, S.; Arfuso, F.; Dharmarajan, A.; Kumar, A.P.; Ramar, P.S.; Looi, C.Y.; et al. Cancer prevention and therapy through the modulation of transcription factors by bioactive natural compounds. Semin. Cancer Biol. 2016, 40-41, 35-47. [CrossRef]

20. Tran, L.; Allen, C.T.; Xiao, R.; Moore, E.; Davis, R.; Park, S.J.; Spielbauer, K.; Van Waes, C.; Schmitt, N.C. Cisplatin Alters Antitumor Immunity and Synergizes with PD-1/PD-L1 Inhibition in Head and Neck Squamous Cell Carcinoma. Cancer Immunol. Res. 2017, 5, 1141-1151. [CrossRef]

21. Szturz, P.; Cristina, V.; Herrera Gomez, R.G.; Bourhis, J.; Simon, C.; Vermorken, J.B. Cisplatin Eligibility Issues and Alternative Regimens in Locoregionally Advanced Head and Neck Cancer: Recommendations for Clinical Practice. Front. Oncol. 2019, 9, 464. [CrossRef] [PubMed]

22. Pincinato, E.C.; Costa, E.F.D.; Lopes-Aguiar, L.; Nogueira, G.A.S.; Lima, T.R.P.; Visacri, M.B.; Costa, A.P.L.; Lourenco, G.J.; Calonga, L.; Mariano, F.V.; et al. GSTM1, GSTT1 and GSTP1 Ile105Val polymorphisms in outcomes of head and neck squamous cell carcinoma patients treated with cisplatin chemoradiation. Sci. Rep. 2019, 9, 9312. [CrossRef] [PubMed]

23. Li, X.; Guo, S.; Xiong, X.K.; Peng, B.Y.; Huang, J.M.; Chen, M.F.; Wang, F.Y.; Wang, J.N. Combination of quercetin and cisplatin enhances apoptosis in OSCC cells by downregulating XIAP through the NF-kappaB pathway. J. Cancer 2019, 10, 4509-4521. [CrossRef] [PubMed]

24. Chang, W.M.; Chang, Y.C.; Yang, Y.C.; Lin, S.K.; Chang, P.M.; Hsiao, M. AKR1C1 controls cisplatin-resistance in head and neck squamous cell carcinoma through cross-talk with the STAT1/3 signaling pathway. J. Exp. Clin. Cancer Res. 2019, 38, 245. [CrossRef] [PubMed]

25. Britt, E.L.; Raman, S.; Leek, K.; Sheehy, C.H.; Kim, S.W.; Harada, H. Combination of fenretinide and ABT-263 induces apoptosis through NOXA for head and neck squamous cell carcinoma treatment. PLoS ONE 2019, 14, e0219398. [CrossRef] [PubMed]

26. Yang, C.Y.; Meng, C.L. Regulation of PG synthase by EGF and PDGF in human oral, breast, stomach, and fibrosarcoma cancer cell lines. J. Dent. Res. 1994, 73, 1407-1415. [CrossRef] [PubMed]

Sample Availability: Samples of the compounds are not available from the authors. 